\title{
BMJ Open How valid are projections of the future prevalence of diabetes? Rapid reviews of prevalence-based and Markov chain models and comparisons of different models' projections for England
}

\author{
Gwyn Bevan (D) , ${ }^{1}$ Chiara De Poli (D) , ${ }^{1}$ Mi Jun Keng (D) , ${ }^{1}$ Rosalind Raine (1) ${ }^{2}$
}

To cite: Bevan G, De Poli C, Keng MJ, et al. How valid are projections of the future prevalence of diabetes? Rapid reviews of prevalencebased and Markov chain models and comparisons of different models' projections for England. BMJ Open 2020;10:e033483. doi:10.1136/ bmjopen-2019-033483

- Prepublication history and additional material for this paper are available online. To view these files, please visit the journal online (http://dx.doi. org/10.1136/bmjopen-2019033483).

Received 13 August 2019 Revised 23 December 2019 Accepted 06 January 2020

Check for updates

(C) Author(s) (or their employer(s)) 2020. Re-use permitted under CC BY. Published by BMJ.

${ }^{1}$ Department of Management, London School of Economics and Political Science, London, UK

${ }^{2}$ Department of Applied Health Research, University College London, London, UK

Correspondence to Professor Gwyn Bevan; r.g.bevan@Ise.ac.uk

\section{ABSTRACT}

Objectives To examine validity of prevalence-based models giving projections of prevalence of diabetes in adults, in England and the UK, and of Markov chain models giving estimates of economic impacts of interventions to prevent type 2 diabetes (T2D).

Methods Rapid reviews of both types of models. Estimation of the future prevalence of T2D in England by Markov chain models; and from the trend in the prevalence of diabetes, as reported in the Quality and Outcomes Framework (QOF), estimated by ordinary least squares regression analysis.

Setting Adult population in England and UK. Main outcome measure Prevalence of T2D in England and UK in 2025

Results The prevalence-based models reviewed use sample estimates of past prevalence rates by age and sex and projected population changes. Three most recent models, including that of Public Health England (PHE), neither take account of increases in obesity, nor report Confidence Intervals (Cls). The Markov chain models reviewed use transition probabilities between states of risk and death, estimated from various sources. None of their accounts give the full matrix of transition probabilities, and only a minority report tests of validation. Their primary focus is on estimating the ratio of costs to benefits of preventive interventions in those with hyperglycaemia, only one reported estimates of those developing T2D in the absence of a preventive intervention in the general population.

Projections of the prevalence of T2D in England in 2025 were (in millions) by PHE, 3.95; from the QOF trend, 4.91 and by two Markov chain models, based on our review, 5.64 and 9.07.

Conclusions To inform national policies on preventing T2D, governments need validated models, designed to use available data, which estimate the scale of incidence of T2D and survival in the general population, with and without preventive interventions.

\section{INTRODUCTION}

Rigorous analysis of worldwide trends of increases in the preventable onset of type 2 diabetes (T2D) in adults justifies a call for
Strengths and limitations of this study

- We undertook rapid reviews of prevalence-based models and Markov chain models, which have been used to give projections of the future prevalence of diabetes to examine their data sources and assumptions.

- We compared projections of the future prevalence of diabetes in England from: reports for the prevalencebased models; our own Markov chain models (based on transition probabilities from our review) and the trend in the prevalence of diagnosed diabetes as reported by general practitioners in England (estimated by ordinary least squares regression analysis).

- This study's limitations are that our reviews were rapid and our models are transparent and simple.

the urgent of implementation of 'populationbased interventions that prevent diabetes, enhance its early detection and use lifestyle and pharmacological interventions to prevent or delay its progression to complications'. ${ }^{1}$ In March 2015, National Health Service (NHS) England and Public Health England (PHE) launched, at scale, the NHS Diabetes Prevention Programme (NDPP), which is a pragmatic lifestyle intervention that targets adults with raised levels of glycated haemoglobin (HbA1c) or a fasting plasma glucose (FPG). ${ }^{2}$ The NDPP aims 'to significantly reduce the 4 million people in England otherwise expected to have T2D by 2025' based on evidence from 'well-designed randomised controlled trials in Finland, the USA, Japan, China and India'. ${ }^{3}$ Many studies have used Markov chain models to estimate the impacts of such preventive interventions using transition probabilities between states: 'normoglycaemia' and 'intermediate hyperglycaemia (IH)' (glucose levels associated with a low and high risks of developing T2D), T2D and 


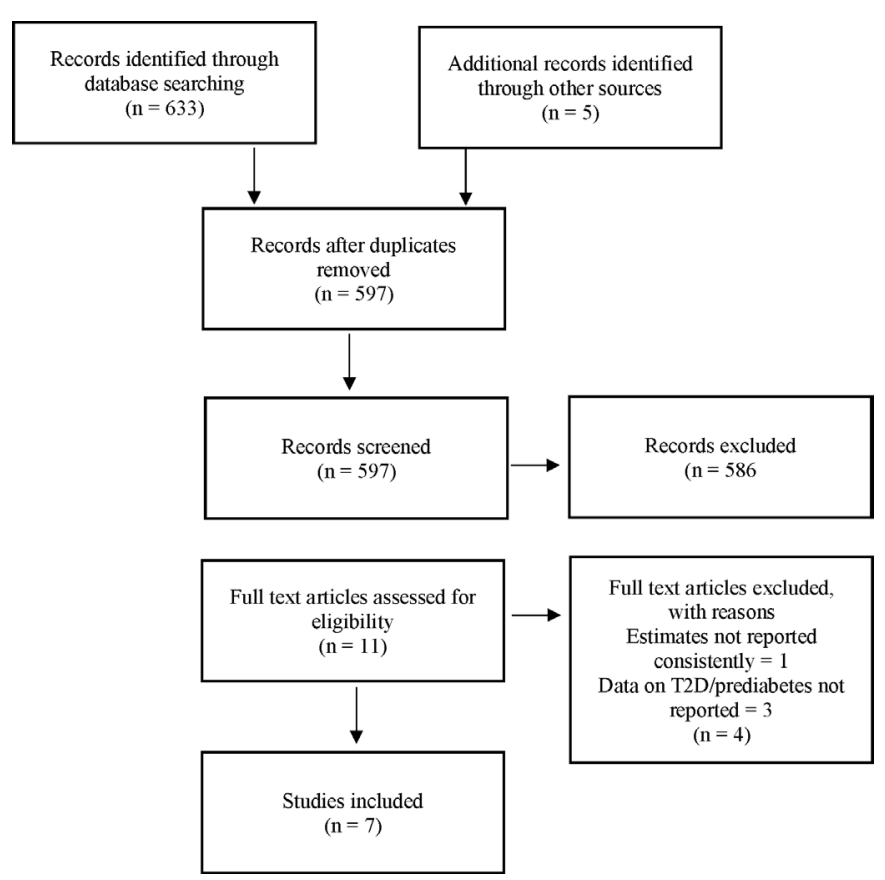

Figure 1 Review flow chart of epidemiological models. T2D, type 2 diabetes.

death. When we tried to use these models, ${ }^{4}$ we had difficulty in finding details from published models, and the models we did develop gave projections of the future prevalence of T2D in 2025 in England, in the absence of a preventive intervention, which were much higher than 4 million. That estimate is based on PHE's prevalence-based model $^{5}$ that gives future projections of the prevalence of T2D (at future time $\mathrm{t}, \mathrm{N}(\mathrm{t})$ ) by multiplying projections of the country's population by age and sex (at time $\mathrm{t}(\mathrm{P}(\mathrm{t}))$ by projections of age-specific prevalence of diabetes (at

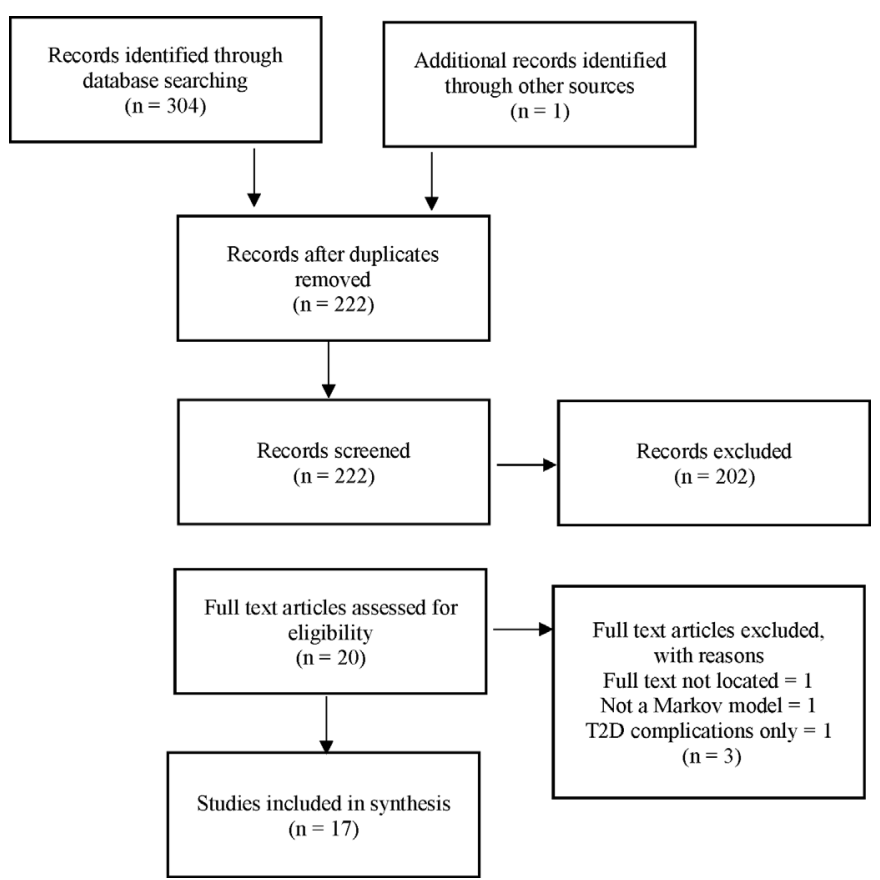

Figure 2 Review flow charts of Markov chain models. T2D, type 2 diabetes. time $\mathrm{t}, \mathrm{D}(\mathrm{t})) .(\mathrm{N}(\mathrm{t})=\mathrm{D}(\mathrm{t}) * \mathrm{P}(\mathrm{t}))$.) Hence this study, which had three aims. First, to compare the model used by PHE to project the prevalence of diabetes in England with other models applied to England and the UK. Second, to identify Markov chain models, we could use to project the prevalence of T2D in England. Third, to compare projections for England of prevalence of diabetes and T2D from different models.

Although we have used England for the purpose of comparing projections by these different models, our study raises general questions about their validity. And hence of the evidence available to governments assessing the urgency of preventing T2D and choosing between different interventions. We consider only adults with diabetes. We use 'diabetes' to cover all types of diabetes, T2D for adults with type 2, 'true' prevalence for both diagnosed and undiagnosed diabetes and T2D.

\section{METHODS}

\section{Rapid reviews}

Our comparisons of projections of different models builds on two reviews of the literature, which were designed to be rapid (not systematic): 'a type of knowledge synthesis in which components of the systematic review process are simplified or omitted to produce information in a short period of time' ${ }^{6}$ We used stringent criteria to identify the principal methods of each type of model. These reviews were undertaken in March 2018, of articles published at any time available on Web of Science and PubMed, which together provide a comprehensive coverage of the literature in the medical and applied health research fields. (The search strategy of each review is given in online supplementary appendix 1.) Articles included in each review were critically appraised and technical specifications of the models and projections were extracted and tabulated. The flow charts in figures 1 and 2 show the screening process.

Rapid review 1 aimed to identify primary studies published from 2010 of models giving estimates of the prevalence of diabetes in adults in England or the UK. We examined how the models take account of future changes in age-specific prevalence rates and test their validity.

Rapid review 2 aimed to identify primary studies using Markov chain models that reported results of interventions to prevent T2D. We reviewed articles using Markov models to run economic analyses, utility analyses and cost-effectiveness analyses of preventive interventions including people diagnosed with IH according to different measures: HbAlc, FPG, Impaired Fasting Glucose (IFG) and Impaired Glucose Tolerance (IGT). (Definitions are given in online supplementary appendix 1.) We reviewed the transition probabilities of the different models, and whether they were used to estimate the future prevalence of T2D without a preventive intervention and tests of validation. In our discussion, we refer to the systematic review by Leal $e t a l^{7}$ of models of pre-diabetes populations used 


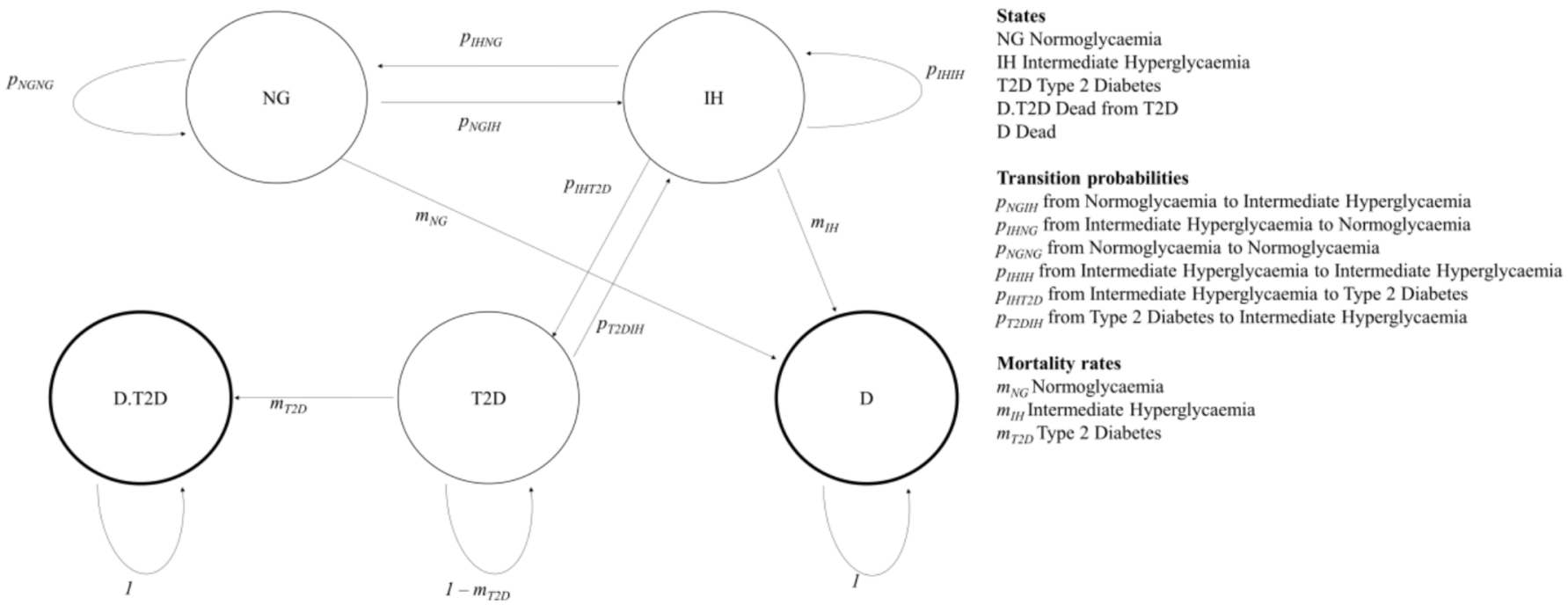

Figure 3 Our Markov chain model.

for reported economic outcomes or evaluations, which has been recently published.

\section{Our Markov chain models}

Our Markov chain models are in Excel (see figure 3) and based on a cycle length of 1 year. The transition probabilities between states other than death are based on rapid review 2. We estimated English mortality rates using the following data sources: age distributions for those with $\mathrm{IH}$ and diabetes, from combined Health Surveys for England (HSE) data (from 2009 to 2013) ${ }^{8}$; mortality rates by age, from the Office of National Statistics (for 2015) ${ }^{9}$; Hazard Ratios (HRs) for those with diabetes (1.32) and T2D (1.28) with reference to those without diabetes, from the National Diabetes Audit (for 2015-2016). ${ }^{10}$ We estimated mortality rates for those with IH using HRs with reference to those with normoglycaemia as estimated (with $95 \%$ CIs) by a systematic review and meta-analysis ${ }^{11}$ : for IGT 1.32 (1.23 to 1.40) and for HbA1c 0.97 (0.88 to 1.07). We used 1.32 for IGT, but 1 for HbAlc because the estimate of 0.97 is not significantly different from 1 . We estimated mortality rates as follows, for 2015, for the English population: for normoglycaemia, $0.6 \%$ (compared with $0.9 \%$ for the general adult population); for $\mathrm{IH}, 1.9 \%$ and $2.3 \%$ for HbA1c and IGT; and for T2D, 2.3\% and 2.2\% for HbA1c and IGT. The probability of remaining in a state was derived as the residual (so all transition probabilities from each state sum to one).

In making future projections of the prevalence of T2D in England, without a preventive intervention, up to 2035, we used PHE estimates for 2015 of those with diabetes ${ }^{12}$ and $\mathrm{IH}^{13}$ and derived the estimate of those with normoglycaemia as the residual for the population of England. ${ }^{14}$ Given doubts over the reliability of diagnosing $\mathrm{IH}^{15}$ we examined the robustness of our results by using the PHE estimate ( $\mathrm{IH}=5.05$ million), and the extreme value of 0 $(\mathrm{IH}=0)$. The data sources of our estimates for England, of the prevalence of diabetes, IH and normoglycaemia; and of mortality rates of those with T2D, IH and normoglycaemia are given in the text.

\section{Estimating the trend in diagnosed diabetes}

We estimated, by OLS regression analysis (using R), ${ }^{16}$ the trend increase in the reported prevalence of diabetes as diagnosed by general practitioners in England, in the Quality Outcomes Framework (QOF) from 2004-2005 (2004) to $2017-2018$ (2017)). ${ }^{17}$ We used these estimates to give projections of the future prevalence of diagnosed diabetes to 2035 .

\section{Comparing projections of the prevalence of diabetes}

We compared three sets of projections of the prevalence of diabetes and T2D in England from:

- Different prevalence-based models.

- The trend in QOF data.

- Our Markov chain models.

The ratios we used for making comparisons across different estimates and their sources are as follows:

- $75 \%$ for the ratio of diagnosed to the true prevalence of diabetes. $^{1819}$

- $90 \%$ for the ratio of the prevalence of T2D to diabetes. ${ }^{12}$

\section{Patients and public involvement}

Patients and the public were not involved in this research study.

\section{RESULTS}

Rapid review 1: methods of prevalence-based models

Rapid review 1 of methods of prevalence-based models retrieved 633 articles and from their citations we identified a further five by snowballing. ${ }^{20}$ After removing duplicates, we screened 597 articles, of which 11 were relevant and fully assessed. After reviewing the full articles, five were excluded and seven were included in our analysis. ${ }^{51821-25}$ This review identified four different underlying models described in 
Table 1 Methods of prevalence-based models

\begin{tabular}{|c|c|c|c|c|c|}
\hline Model & Method of estimation & $\begin{array}{l}\text { Prevalence } \\
\text { rates used for } \\
\text { projections }\end{array}$ & $\begin{array}{l}\text { Validation } \\
\text { against QOF } \\
\text { data? }\end{array}$ & Model validation? & Cls? \\
\hline Shaw et $a l^{21}$ & Logistic regression & Age and sex & No & No & No \\
\hline Guariguata et $a l^{26}$ & Logistic regression & $\begin{array}{l}\text { Age and sex, and } \\
\text { urban/rural }\end{array}$ & No & No & No \\
\hline $\begin{array}{l}\text { Association of } \\
\text { Public Health } \\
\text { Observatories }^{1825}\end{array}$ & $\begin{array}{l}\text { Direct estimation from } \\
\text { HSE for age, sex and } \\
\text { IMD. Trend in obesity } \\
\text { estimated by linear } \\
\text { regression. }\end{array}$ & $\begin{array}{l}\text { Age and sex, IMD } \\
\text { (2004), Ethnicity and } \\
\text { increases in obesity }\end{array}$ & $\begin{array}{l}\text { Yes for } \\
2008 / 2009\end{array}$ & No & Yes \\
\hline $\mathrm{PHE}^{5}$ & Logistic regression & $\begin{array}{l}\text { Age and sex, } \\
\text { ethnicity, IMD } 2015\end{array}$ & $\begin{array}{l}\text { Yes for } \\
2014 / 2015\end{array}$ & $\begin{array}{l}\text { Yes: refitting model } \\
\text { on } 70 \% \text { of data and } \\
\text { assessing against } \\
\text { remaining } 30 \%\end{array}$ & No \\
\hline
\end{tabular}

HSE, Health Surveys for England; IMD, Index of Multiple Deprivation; PHE, Public Health England; QOF, Quality and Outcomes Framework.

table 1, which have been used to give five different projections of the future prevalence of diabetes for England and the UK. Two models produce global estimates: Shaw $e t a l,{ }^{21}$ Guariguata $e t a l,{ }^{26}$ which is used by Whiting $e t a t^{22}$ and Guariguata $e t a t^{23}$; and two for England only, the PHE model, ${ }^{5}$ and the Association of Public Health Observatories (APHO) Diabetes Prevalence Model,${ }^{18}$ which is used by Hex et $a t^{24}$ and Gatineau et $a t^{25}$

Each prevalence-based model uses: projected population changes; and estimates of the true age-specific prevalence rates of diabetes, from past annual HSE, which are subject to two limitations. First, the small size of the sample means that the point estimate for the year of the survey is surrounded by large CI estimates. Gatineau et al indicate that the HSE survey for 2013 gives point estimate of prevalence of $7.3 \%$ with CI estimates ranging from $4.3 \%$ to $10.3 \% .{ }^{25}$ The PHE model ${ }^{5}$ reduces the sampling error from HSE by using 3 years of data (2012, 2013 and 2014). Second, the HSE estimates of prevalence are based on those who self-reported a diabetes diagnosis made by a doctor (by HbA1c or FPG); and, for those who have not been diagnosed and agreed to have a blood test, having a HbAlc value of $6.5 \%$ or more. ${ }^{5}$ Hence these estimates may be in error because of poor reliability of self-reporting or because of actual diagnostic errors. Barry et al (p. 9) report that 'The most commonly used test (HbA1c) is neither sensitive nor specific; the fasting glucose test is specific but not sensitive'. ${ }^{15}$ Holman et al (p.6) pointed out, however, that 'Although HbA1c and fasting identify different groups of people with undiagnosed diabetes, the proportion of people that are identified is similar'. ${ }^{18}$

Our review aimed to answer two questions about the models.

1. How were the models validated? A basic test of the va-

lidity of a forecasting model is to apply this to past data to predict a known future for example, does the model using HSE data from 2004 predict prevalence as estimated from HSE data in 2014? None of the accounts of the models we reviewed reports such a test. The PHE model $^{5}$ was validated by refitting the model on $70 \%$ of the data (randomly selected) and checking its estimates against the remaining $30 \%$ of data.

2. Did the models try to take account of future changes in age-specific prevalence rates? Only the APHO model ${ }^{18}$ aimed to do this by estimating the net effect of trends in: changes in ethnicity; and being overweight and obese to create a sex-specific obesity adjustment index. They did not, however, give details of how that index was modelled. The other three models ${ }^{5126}$ assumed that future age-specific prevalence of diabetes would be as estimated from past HSEs.

The prevalence-based models we reviewed are focused on estimating geographical variations in the future prevalence of diabetes within countries, rather than giving sound estimates of future totals.

\section{Rapid review 2: Markov chain models}

Rapid review 2 of Markov models identified 304 articles. An additional one was snowballed. After removing duplicates, 222 articles were screened, 20 of them were considered relevant and fully assessed. Of these, one was excluded because we could not locate it, one did not report the results, and one modelled the progression from diabetes to its complications only. Table 2 gives details of the remaining 17 articles, ${ }^{27-43}$ ordered in terms of their completeness of the information we could find on transition probabilities. (online supplementary appendix 2 gives additional information on objectives, model, population, outcomes, sensitivity analysis and validation.) Two articles did not report the measure of IH used. ${ }^{39} 43$ Twelve reported a model using one risk measure only: nine models used IGT, $282931-34373842$ two HbA1c ${ }^{3640}$ and one FPG only. ${ }^{27}$ Neumann et al reported two models, using IFG and IGT $^{28}$; and Roberts et $a l^{35}$ three models using HbAlc, IGT and IFG. Hence, we reviewed 20 models. 


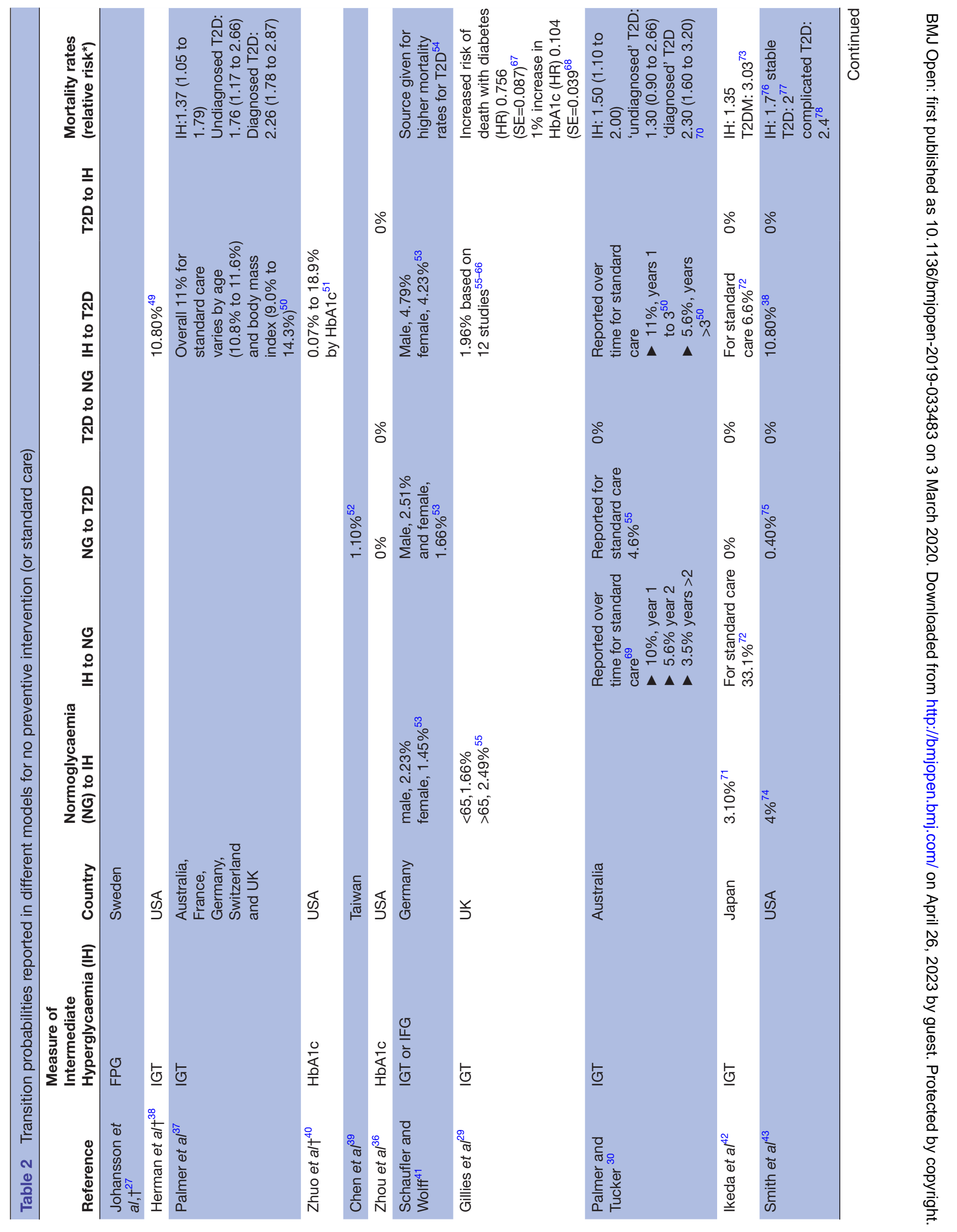




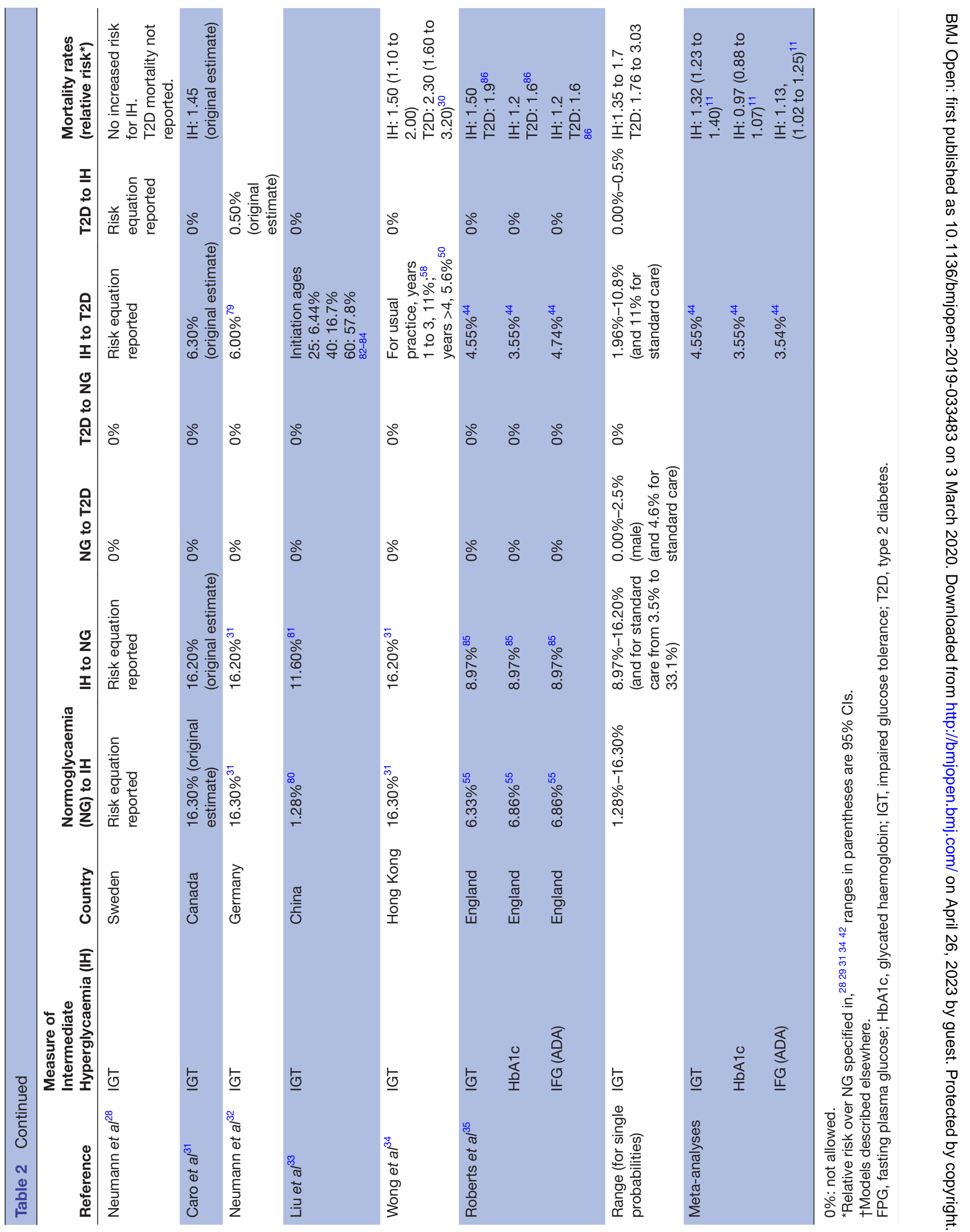


Our objective was to develop a matrix of transition probabilities, with one transition probability only between states, and hence designed to use available data for England. Table 2 gives the transition probabilities we found and shows no article provided the complete matrix of transition probabilities. Five only reported the full set between states other than death. No article reports transition probabilities from different states to death (ie, mortality rates for each state) and, where relative risk of mortality is reported for IH and T2D, we could not always find whether this was compared with normoglycaemia. Nor could we find how these models satisfied the fundamental requirement of a Markov chain model that all transition probabilities out of a state, estimated from different datasets, (including return to that state) sum to one.

Our review aimed to answer three questions about the Markov chain models:

1. Do these articles provide evidence of the likely impact of national preventive programmes? The primary focus of the articles we reviewed is on estimating the ratio of costs to benefits of preventive interventions for those who are hyperglycaemic (most based on IGT, only three for HbA1c, two for IFG and one for FPG). None reported the impact of preventive interventions on reducing the burden of disease from T2D in the general population. Only four articles ${ }^{19} 253140$ modelled the general population (with normoglycaemia and $\mathrm{IH}$ ).

2. How were the models validated? Whereas most articles reported outcomes of sensitivity analyses, only five reported comparisons of their models' outputs with other empirical data: clinical trials ${ }^{23}{ }^{32}$; the population with T2D in southern Wisconsin ${ }^{36}$; the disease progression of T2D in Germany ${ }^{33}$; mortality data for England and estimates of current prevalence of T2D by age group. ${ }^{27}$ A good empirical test of a model's validity is of its estimates of those developing T2D in the absence of a preventive intervention. Only Caro $e t a l^{31}$ reported this for a general population, but they did not report a check against other projections. Of the articles that modelled populations with $\mathrm{IH}$, only three reported estimates of the percentages developing T2D in the absence of intervention. 152324

3. How do transition probabilities compare? All models, except that of Neumann $e t a l,{ }^{32}$ allow transitions from T2D to T2D or death only. Neumann et a ${ }^{32}$ allow transition (at a low probability, $0.5 \%$ ) from T2D to IH (IGT) (because 'this transition exists but seldom occurs', p
4). Only two models allow transition from normoglycaemia directly to T2D: Schaufler and Wolff ${ }^{41}$ (IFG or IGT_-for males, $2.51 \%$ and females, $1.66 \%$ ) and Smith et al (measure of IH not specified, $0.40 \%) .{ }^{43}$ For the transition probabilities reported in table 2 , two models allow for changes over time ${ }^{2326}$; and seven for variations by age. ${ }^{20-23252930}$ Table 2 shows that wide ranges of transition probabilities used by the different IGT models: from normoglycaemia to IH, $1.28 \%-16.30 \%$; from IH to low, $8.97 \%-16.20 \%$; normoglycaemia to T2D, $0.00 \%-2.51 \%$ (for males); IH to T2D, $1.96 \%-$ $10.8 \%$. A meta-analysis recommended a rate of $4.55 \%$ for the last. ${ }^{44}$

The relative risks reported for IH for IGT ranged from 1.35 to 1.7 ; and T2D from 1.76 to 3.03 . Roberts $e$ t $a l^{35}$ report these risks for $\mathrm{HbAlc}$ to be 1.2 and 1.6. The estimates from the systematic review and meta-analysis ${ }^{11}$ for IH were: for IGT 1.32 (1.23-1.40) and for HbA1c $0.97(0.88-1.07)$. One article $^{32}$ reported a matrix in which probabilities of transitions between states other than death sum to one, which implies no one dies. PHE defines those with IH using either HbAlc or IFG. ${ }^{5}$ The models developed by Roberts $e t a l^{35}$ for HbA1c and IFG are similar. We used their HbAlc model to project the prevalence of T2D in England. They used the recommended transition probabilities from different risk measures of IH to T2D identified by a meta-analysis. ${ }^{44}$ Neumann $e t a \hat{l}^{2}$ and Caro $e t a \hat{l}^{11}$ have similar transition probabilities, which are higher than those of Roberts et $a l,{ }^{35}$ for IGT from normoglycaemia to IH, and IH to T2D: $16.3 \%$ and $6.00 \%$ compared with $6.33 \%$ and $4.55 \%$. We used the transition probabilities used by Neumann et $a l^{32}$ because that is more recent. Model 1 is based on Roberts et al (HbA1c), ${ }^{35}$ which was modified as model 2 to give the projections of PHE. To do this, model 2's transition probability from IH to T2D (0.013) is a third of that of model 1 (0.036), and below the lowest rate of any model we reviewed (0.02). (Model 2 has a corresponding increase in the transition probability of remaining in IH $(0.836$ to 0.878$)$ ). Model 3 is based on Neumann et al. ${ }^{32}$ Details of the models are given in online supplementary appendix 1 .

\section{Estimating the trend in diagnosed diabetes}

Table 3 reports the OLS estimate of the trend in diagnosed diabetes from QOF data, ${ }^{17}$ which gives an annual rate of increase of $0.11 \%$.

\begin{tabular}{lclllll}
\hline \multicolumn{1}{l}{ Table 3} & The trend model from QOF data & & & & \\
\hline Coefficients & Value & SE & T & Pr > |T| & Lower bound (95\%) & Upper bound (95\%) \\
\hline Intercept & -219 & 4.375 & -50.14 & $<0.0001$ & -210 & -229 \\
Year & 0.110 & 0.002 & 50.71 & $<0.0001$ & 0.105 & 0.115 \\
Adjusted R squared & 0.995 & & & & \\
\hline
\end{tabular}

QOF, Quality and Outcomes Framework. 


\section{Comparing projections of the future prevalence of T2D}

Table 4 gives: for the different prevalence-based models their defined populations, data sources and projections of diabetes true prevalence (in millions); comparable estimates of the true prevalence of diabetes from the QOF data and estimated trend (increased by a third) and the annual rate of increase in prevalence from the first in the series to the last. Table 4 shows that for the three models that do not allow for increase in prevalence rates by age and sex, ${ }^{21-23}$ the older the HSE data used, the lower is the estimate of the rate of increase in prevalence for England. We compare projections of true prevalence of diabetes and T2D by different models giving numbers in millions; and, in parentheses, CIs (where available).

Global models give three projections of the true prevalence for diabetes prevalence in the UK (aged 20-79): for $2030,2.55^{21}$ and $3.65^{22}$ and 2035, 3.62. ${ }^{23}$ Each projection is below the estimate by $\mathrm{PHE}^{12}$ for England for 2015, 3.81 (based on HSEs for 2012, 2103 and 2014). These global models assume low rates of increase in prevalence over time and exclude those over 79, who we estimated to account for over $25 \%$ of the number who would be aged 20 to 79 in England and develop diabetes in 2030 and 2035 . The projections by these global models are not examined further.

Two models give projections of the true prevalence of diabetes for England only (aged over 15): the PHE model ${ }^{12}$ for 2030, 4.68 and 2035, 4.94 and APHO for 2030, 4.60 (3.25 to 6.88). ${ }^{18}$ The two accounts of the APHO model ${ }^{1516}$ report the same projection for 2030; but one estimated the prevalence of diabetes in $2010(3.10)^{18}$ to be higher than the other for 2013 (2.17). ${ }^{16}$ And the increase in prevalence to 2030 attributed to increases in obesity was estimated to be a half ${ }^{18}$ and a third. ${ }^{25}$ Figure 4 compares three projections for 2025: $\mathrm{PHE},{ }^{12}$ 4.39; Holman et al 4.19 (2.93-6.19); and the QOF trend, 5.46 (5.32-5.59), which has a narrow CI because this trend has been so stable.

Figure 5 compares projections of the true prevalence of T2D in England to 2035, the QOF trend and our three Markov chain models. This shows that the projections by model 2 replicated the projections by PHE; by model 1 are above those from PHE and the QOF trend; by model 3 seem to be implausibly explosive. Figure 5 also shows the impact of reducing the estimate of those with IH to zero in 2015 on the projections by models 1 and 3 . Table 5 gives projections for 2025, These are: 3.95 , by PHE; 4.91 (4.79-5.03) from the QOF trend; 5.64 by model $1 ; 3.86$ by model 2 and 9.07 by model 3 . Putting the estimate of those with IH to zero in 2015 reduces the projections by models 1 and 3 to 5.01 and 8.57 , which are above the projections by PHE and the QOF trend.

\section{DISCUSSION}

Akushevich $e t a t^{45}$ point out that although the "prevalence probability of a disease is a fundamental epidemiological characteristic' for which there are various data sources, this random variable is the difference between changes

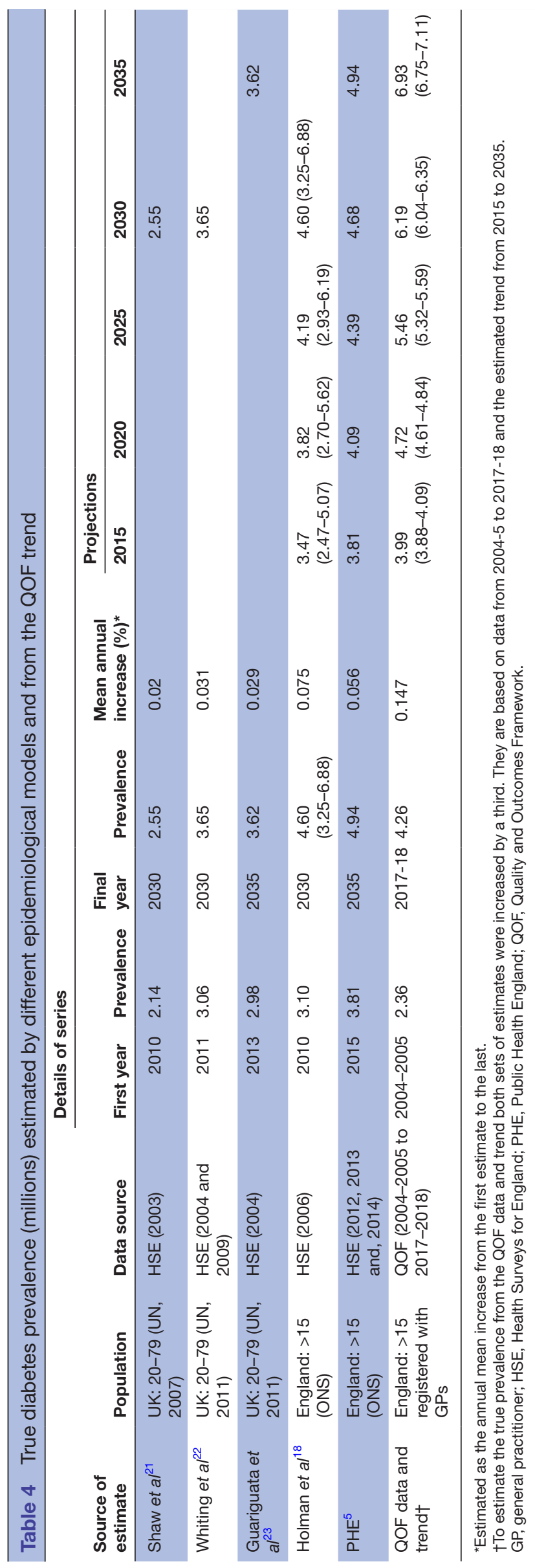




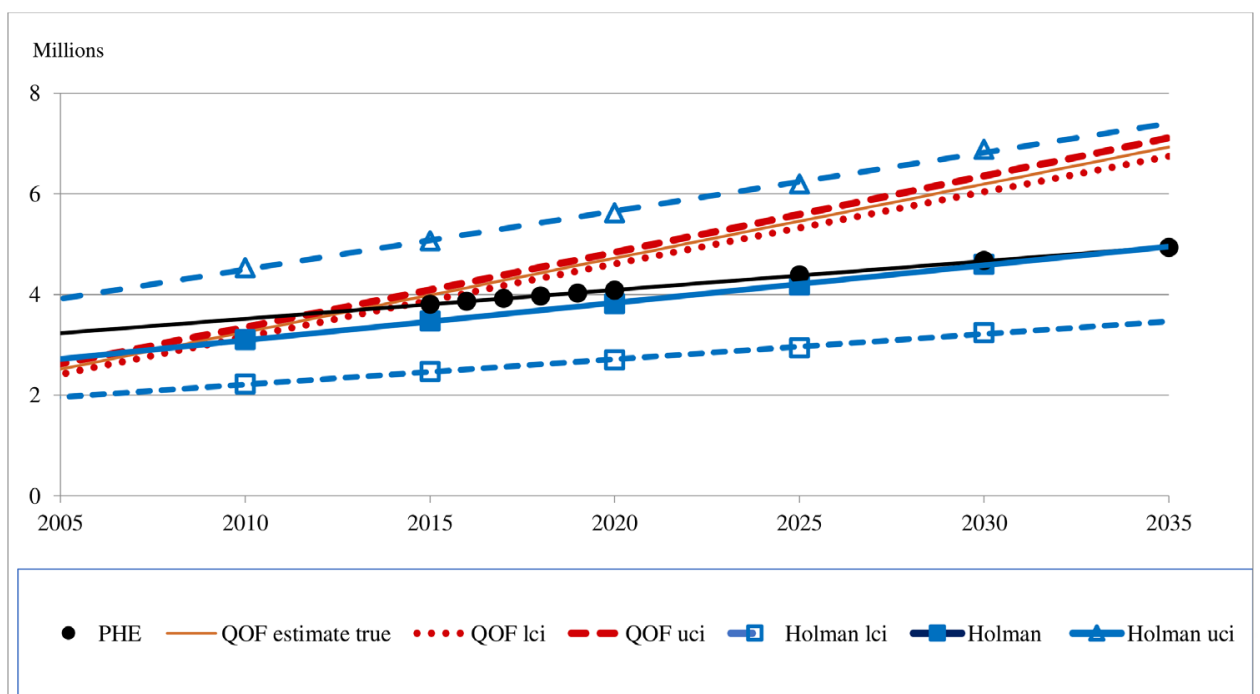

Figure 4 Projections of true diabetes prevalence in England: 2005-2035. PHE, Public Health England; QOF, Quality and Outcomes Framework.

over time in disease incidence and patient survival. This has a statistical implication that, whatever modelling approach is used, we would expect projections of prevalence to have large errors of estimation. The policy implication, which Akushevich et al emphasise, is that the overriding objective ought to be to improve population health, rather than reducing the prevalence of T2D: because, for example, improving survival of those with T2D may increase prevalence (depending on changes in incidence). Akushevich et al developed a new methodological approach that partitions trends in observed disease prevalence into their two components, and hence gives estimates of the direction and strength of the effect of each. Their models are estimated from a single data set (Medicare data), incorporate changes over time and take account of age.

The four prevalence-based models we reviewed ${ }^{10141517}$ use past estimated prevalence rates by age and sex and projected changes in populations. They are focused on estimating geographical variations in the future prevalence of diabetes within countries, rather than giving sound estimates of future totals. Only one model aims to take account of changes in prevalence rates by age and sex over time. ${ }^{15}$ Of the five projections of diabetes prevalence, for England and the UK we reviewed, ${ }^{10-12} 1415$ only one ${ }^{15}$ reported CIs.

The Markov chain models of the economic impacts of interventions that aim to prevent T2D, which we reviewed, aim to capture changes in incidence and survival in one model. Their primary focus is on estimating the ratio of costs to benefits of preventive interventions for those who are hyperglycaemic (mostly based on IGT). None reported the impact of preventive interventions on reducing the burden of disease from T2D in the general population. We could not find a complete matrix of transition probabilities; nor descriptions of how transition probabilities estimated from different datasets satisfied the fundamental requirement of a Markov chain

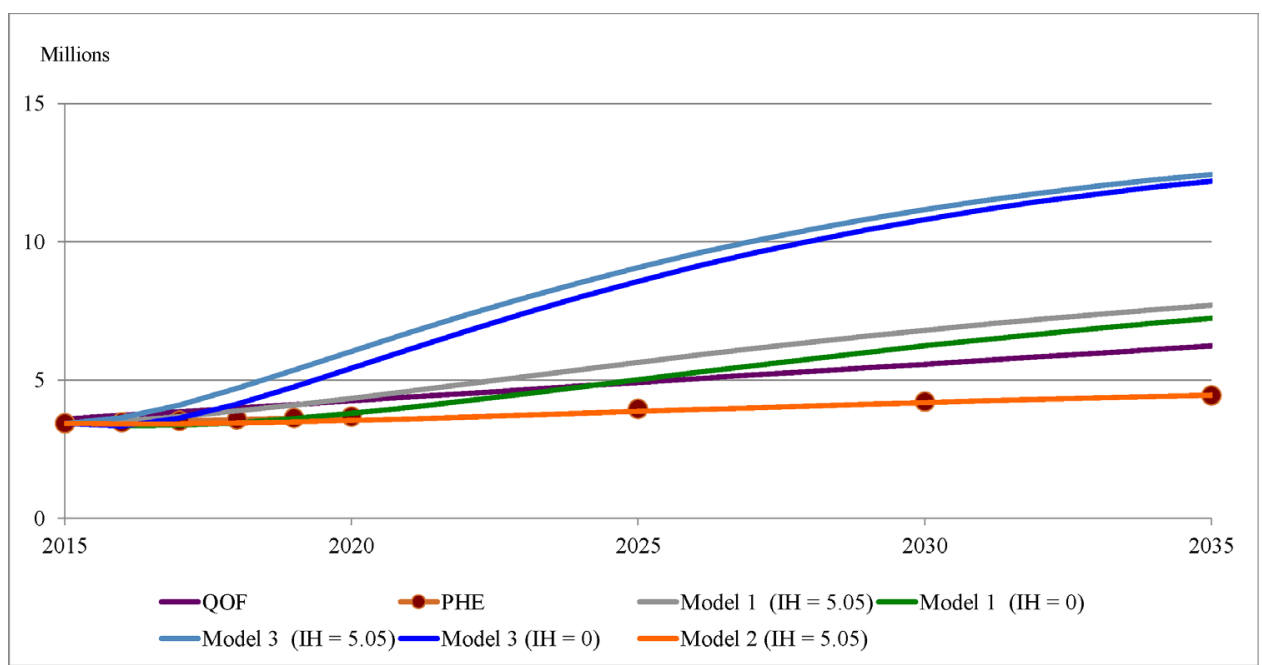

Figure 5 Projections of the true prevalence of T2D in England: 2015-2035. PHE, Public Health England; QOF, Quality and Outcomes Framework; T2D, type 2 diabetes. 
Table 5 Projections of the true prevalence of T2D in England for 2025

\section{Projections for 2025 (millions)}

Markov (numbers with intermediate hyperglycaemia in

Statistical 2015)

\begin{tabular}{|c|c|c|c|c|}
\hline \multirow[b]{2}{*}{ Model } & \multicolumn{2}{|l|}{ Statistical } & \multicolumn{2}{|l|}{ 2015) } \\
\hline & $\begin{array}{l}\text { Point } \\
\text { estimate }\end{array}$ & $95 \%$ Cls & $5.05^{*}$ & Zero \\
\hline PHE & 3.95 & n.a. & & \\
\hline $\begin{array}{l}\text { QOF } \\
\text { trend }\end{array}$ & 4.91 & 4.79 to 5.03 & & \\
\hline Model $1 \dagger$ & & & 5.64 & 5.01 \\
\hline Model 2ł & & & 3.86 & \\
\hline Model $3 \S$ & & & 9.07 & 8.57 \\
\hline
\end{tabular}

${ }^{*}$ As estimated by $\mathrm{PHE}$

†Based on Roberts et al. ${ }^{35}$

‡Based on Roberts et al ${ }^{35}$ but modified to reproduce the PHE trend to 2035.

§Based on Neuman et al. ${ }^{32}$

n.a., not available; PHE, Public Health England; QOF, Quality and

Outcomes Framework; T2D, type 2 diabetes.

model that all transition probabilities out of a state sum to one. The transition probabilities we did find do not vary over time. In seven articles these probabilities do vary by age. ${ }^{20-23252930}$ In their systematic review of models of the economic impacts of preventive interventions, Leal et $a l^{7}$ also found the majority of models assumed that 'the rate of progression to T2D was constant across the entire pre-diabetes population'. They attribute this in part to limitations in the available data, but highlight the 'stark contrast' between these simple models and 'The complexity of risk prediction models for diabetes incidence and the variety of covariates used' ${ }^{46}{ }^{47}$ Friedman famously ${ }^{48}$ argued, however, that the relevant question to ask about the 'assumptions' of economic theory, 'is not whether they are descriptively realistic ... but whether the theory works, which means that it yields sufficiently accurate predictions' ( $p$ 153).

Three projections of diabetes prevalence (in millions) for the UK (aged 20-79) by global models are: for 2030, $2.55^{21}{ }^{22}$ and $3.65,{ }^{21}{ }^{22}$ and for $2035,3.62 .{ }^{23}$ Each is below the PHE estimate of 3.81 for 2015 for England only (over 15) ${ }^{12}$ This raises questions over the validity of these global projections; and their excision of those over 79, who we estimated to account for over $25 \%$ of the number who would be aged 20 to 79 and develop T2D after 2030. We report three estimates of diabetes prevalence in England for 2025 (with 95\% CIs where available): 4.39 by PHE, ${ }^{12}$ 4.19 (2.93 to 6.19 ) by the APHO model, ${ }^{18}{ }^{25}$ and 5.46 (5.32 to 5.59) from the QOF trend. We and Leal et $a l^{7}$ found only minority of articles reported tests of validation. Such checks are vital for Markov chain models given the different data sources used to estimate transition probabilities.
Our Markov chain models are based on transition probabilities to states other than death from published models, to death from English mortality rates, and of remaining in a state as the residual (so all transition probabilities from each state sum to one). The projections of prevalence of T2D for England for 2025 are: 5.64 by model 1 (based on Roberts et al for HbAlc), ${ }^{35}$ and 9.07 by model 3 (based on Neuman et al for IGT) ${ }^{32}$ To reproduce PHE's projections by model 2, of 3.86, model 1 was modified with a lower probability of transition from IH to T2D than any of the models we reviewed. These comparisons suggest that the PHE projection of T2D prevalence in 2025 of 4 million is too low, and a more realistic estimate is about 5 million.

The limitations of our research are our models are simple and transparent, and, as we did not undertake systematic reviews, we may have omitted relevant articles. The systematic review by Leal $e t a l^{7}$ reviewed 29 studies, which included 12 of the 17 studies of Markov chain models that we reviewed. Their principal findings are strikingly similar to ours. They recommend the development of 'more comprehensive models that are capable of better capturing the continuity in disease progression and, also, of incorporating the identification of novel biomarkers'. But, they recognise such models require more detailed data and only need to be comprehensive enough to provide reliable estimates for decision making.

\section{CONCLUSIONS}

There are three implications of our reviews of two types of models used to project prevalence of T2D. First, current prevalence-based models are focused on estimating geographical variations in the future prevalence of diabetes within countries, rather than giving sound estimates of future totals. They are designed to underestimate the scale of increases in the future prevalence of T2D in England and the UK, and hence the urgency for governments to implement preventive interventions. Second, the primary focus of the Markov chain models is on estimating the ratio of costs to benefits of preventive interventions for those who are hyperglycaemic (mostly based on IGT). We found that no articles gave the complete matrix of transition probabilities and a full description of how they were derived. Only a minority have been subjected to tests of validity. Third, to inform national policies, governments need estimates of the impacts of preventive interventions on reducing the burden of disease from T2D in the general population. These estimates ought to be derived from validated models, designed to use available data, that estimate changes over time in the incidence and survival of patients with T2D, with and without preventive interventions.

Acknowledgements We are grateful to our two referees, Anders Green and Igor Akushevich, for critical comments on earlier drafts. Their comments have clarified our argument and helped us to consider the adequacy of two types of models that project changes in prevalence, given that this is the observed outcome of changes in incidence and survival. 
Contributors MJK did the original work in developing initial Markov Chain models to estimate the impacts of preventive interventions on the future prevalence of Type 2 Diabetes (T2D) in England and has been involved throughout this project. CDP worked with MJK in developing those models, undertook the rapid reviews of epidemiological and Markov Chain models, and commented on drafts of this paper. GB prepared drafts of the paper, reviewed epidemiological and Markov Chain models, developed the models used in this paper and undertook comparisons of projections. RR took part in the workshops on the models, reviewed our methods and findings, and commented on drafts.

Funding This study was funded by the National Institute for Health Research (NIHR) Collaboration for Leadership in Applied Health Research and Care North Thames at Barts Health NHS Trust, which had no role in the writing of the manuscript or the decision to submit it for publication.

Competing interests None declared.

Patient consent for publication Not required.

Provenance and peer review Not commissioned; externally peer reviewed.

Data availability statement All data relevant to the study are included in the article or uploaded as online supplementary information. The data we have used are from cited public sources.

Open access This is an open access article distributed in accordance with the Creative Commons Attribution 4.0 Unported (CC BY 4.0) license, which permits others to copy, redistribute, remix, transform and build upon this work for any purpose, provided the original work is properly cited, a link to the licence is given, and indication of whether changes were made. See: https://creativecommons.org/ licenses/by/4.0/.

\section{ORCID iDs}

Gwyn Bevan http://orcid.org/0000-0003-2123-3770

Chiara De Poli http://orcid.org/0000-0002-1879-553X

Mi Jun Keng http://orcid.org/0000-0001-5979-1706

Rosalind Raine http://orcid.org/0000-0003-0904-749X

\section{REFERENCES}

1 NCD Risk Factor Collaboration (NCD-RisC). Worldwide trends in diabetes since 1980: a pooled analysis of 751 population-based studies with 4.4 million participants. Lancet 2016;387:1513-30.

2 NHS. Primary care toolkit to support local implementation of the NHS DPP. London (UK, 2017.

3 Public Health England, NHS England. National NHS diabetes initiative launched in major Bid to prevent illness, 2015.

4 De Poli C, Bevan G, Keng MJ, et al. Impact of interventions to prevent diabetes in England: a simulation model. The Lancet 2017;390:S36

5 Public Health England. Technical document for the diabetes prevalence model for England 2016. London, 2016.

6 Khangura S, Konnyu K, Cushman R, et al. Evidence summaries: the evolution of a rapid review approach. Syst Rev 2012;1.

7 Leal J, Morrow LM, Khurshid W, et al. Decision models of prediabetes populations: a systematic review. Diabetes Obes Metab 2019;21:1558-69.

8 National Cardiovascular Intelligence Network (NCVIN)- Public Health England. NHS diabetes prevention programme (NHS DPP) nondiabetic hyperglycaemia, 2015.

9 Office for National Statistics. 2014-based national population projections, 2015

10 Healthcare Quality Improvement Partnership (HQIP). National diabetes audit, 2015-16 report 2: complications and mortality, 2017.

11 Huang Y, Cai X, Mai W, et al. Association between prediabetes and risk of cardiovascular disease and all cause mortality: systematic review and meta-analysis. BMJ 2016;355:i5953.

12 National Cardiovascular Intelligence Network (NCVIN) - Public Health England. Prevalence estimates of diabetes, 2016.

13 Public Health England - National Cardiovascular Intelligence Network. Prevalence estimates of non-diabetic hyperglycaemia, 2015.

14 Office for National Statistics. National population projections: 2014-based statistical Bulletin. Off Natl Stat 2015.

15 Barry E, Roberts S, Oke J, et al. Efficacy and effectiveness of screen and treat policies in prevention of type 2 diabetes: systematic review and meta-analysis of screening tests and interventions. BMJ 2017;356:i6538.

16 RStudio Team. RStudio: integrated development for R, 2015.
17 NHS Digital. Quality and Outcomes Framework (QOF) - 2016-17, 2017.

18 Holman N, Forouhi NG, Goyder E, et al. The Association of Public Health Observatories (APHO) diabetes prevalence model: estimates of total diabetes prevalence for England, 2010-2030. Diabet Med 2011;28:575-82.

19 Moody A, Cowley G, Ng Fat L, et al. Social inequalities in prevalence of diagnosed and undiagnosed diabetes and impaired glucose regulation in participants in the health surveys for England series. BMJ Open 2016;6:e010155.

20 Wohlin C. Guidelines for snowballing in systematic literature studies and a replication in software engineering. ACM International Conference Proceeding Series, 2014.

21 Shaw JE, Sicree RA, Zimmet PZ. Global estimates of the prevalence of diabetes for 2010 and 2030. Diabetes Res Clin Pract 2010;87:4-14.

22 Whiting DR, Guariguata L, Weil C, et al. IDF diabetes atlas: global estimates of the prevalence of diabetes for 2011 and 2030. Diabetes Res Clin Pract 2011;94:311-21.

23 Guariguata L, Whiting DR, Hambleton I, et al. Global estimates of diabetes prevalence for 2013 and projections for 2035. Diabetes Res Clin Pract 2014;103:137-49.

24 Hex N, Bartlett C, Wright D, et al. Estimating the current and future costs of type 1 and type 2 diabetes in the UK, including direct health costs and indirect societal and productivity costs. Diabet Med 2012;29:855-62.

25 Gatineau M, Hancock C, Holman N, et al. Adult obesity and type 2 diabetes. London, UK, 2014.

26 Guariguata L, Whiting D, Weil C, et al. The International diabetes Federation diabetes atlas methodology for estimating global and national prevalence of diabetes in adults. Diabetes Res Clin Pract 2011;94:322-32.

27 Johansson P, Östenson C-G, Hilding AM, et al. A cost-effectiveness analysis of a community-based diabetes prevention program in Sweden. Int J Technol Assess Health Care 2009;25:350-8.

28 Neumann A, Lindholm L, Norberg M, et al. The cost-effectiveness of interventions targeting lifestyle change for the prevention of diabetes in a Swedish primary care and community based prevention program. Eur J Health Econ 2017;18:905-19.

29 Gillies CL, Lambert PC, Abrams KR, et al. Different strategies for screening and prevention of type 2 diabetes in adults: cost effectiveness analysis. BMJ 2008;336:1180-5.

30 Palmer AJ, Tucker DMD. Cost and clinical implications of diabetes prevention in an Australian setting: a long-term modeling analysis. Prim Care Diabetes 2012;6:109-21.

31 Caro JJ, Getsios D, Caro I, et al. Economic evaluation of therapeutic interventions to prevent type 2 diabetes in Canada. Diabet Med 2004;21:1229-36.

32 Neumann A, Schwarz P, Lindholm L. Estimating the costeffectiveness of lifestyle intervention programmes to prevent diabetes based on an example from Germany: Markov modelling. Cost Eff Resour Alloc 2011:9:17.

$33 \mathrm{Liu}$ X, Li C, Gong H, et al. An economic evaluation for prevention of diabetes mellitus in a developing country: a modelling study. BMC Public Health 2013;13:729.

34 Wong CKH, Jiao F-F, Siu S-C, et al. Cost-Effectiveness of a short message service intervention to prevent type 2 diabetes from impaired glucose tolerance. J Diabetes Res 2016;2016:1-8.

35 Roberts S, Craig D, Adler A, et al. Economic evaluation of type 2 diabetes prevention programmes: Markov model of low- and high-intensity lifestyle programmes and metformin in participants with different categories of intermediate hyperglycaemia. BMC Med 2018;16.

36 Zhou H, Isaman DJM, Messinger S, et al. A computer simulation model of diabetes progression, quality of life, and cost. Diabetes Care 2005;28:2856-63.

37 Palmer AJ, Roze S, Valentine WJ, et al. Intensive lifestyle changes or metformin in patients with impaired glucose tolerance: modeling the long-term health economic implications of the diabetes prevention program in Australia, France, Germany, Switzerland, and the United Kingdom. Clin Ther 2004;26:304-21.

38 Herman WH, Hoerger TJ, Brandle M, et al. The cost-effectiveness of lifestyle modification or metformin in preventing type 2 diabetes in adults with impaired glucose tolerance. Ann Intern Med 2005;142:323-32.

39 Chen TH-H, Yen M-F, Tung T-H. A computer simulation model for cost-effectiveness analysis of mass screening for type 2 diabetes mellitus. Diabetes Res Clin Pract 2001;54:37-42.

40 Zhuo X, Zhang P, Selvin E, et al. Alternative HbA1c cutoffs to identify high-risk adults for diabetes prevention. Am J Prev Med 2012;42:374-81. 
41 Schaufler TM, Wolff M. Cost effectiveness of preventive screening programmes for type 2 diabetes mellitus in Germany. Appl Health Econ Health Policy 2010;8:191-202.

42 Ikeda S, Kobayashi M, Tajima N. Cost-Effectiveness analysis of voglibose for prevention of type 2 diabetes mellitus in Japanese patients with impaired glucose tolerance. J Diabetes Investig 2010;1:252-8.

43 Smith KJ, Hsu HE, Roberts MS, et al. Cost-Effectiveness analysis of efforts to reduce risk of type 2 diabetes and cardiovascular disease in southwestern Pennsylvania, 2005-2007. Prev Chronic Dis 2010;7:A109.

44 Morris DH, Khunti K, Achana F, et al. Progression rates from HbA1c 6.0-6.4\% and other prediabetes definitions to type 2 diabetes: a meta-analysis. Diabetologia 2013;56:1489-93.

45 Akushevich I, Yashkin AP, Kravchenko J, et al. Identifying the causes of the changes in the prevalence patterns of diabetes in older U.S. adults: a new trend partitioning approach. J Diabetes Complications 2018;32:362-7.

46 Collins GS, Mallett S, Omar O, et al. Developing risk prediction models for type 2 diabetes: a systematic review of methodology and reporting. BMC Med 2011;9.

47 Hippisley-Cox J, Coupland C. Development and validation of QDiabetes-2018 risk prediction algorithm to estimate future risk of type 2 diabetes: cohort study. BMJ 2017:j5019.

48 Friedman M. The methodology of positive economics. In: The philosophy of economics. An Anthology, 2007.

49 The CDC Diabetes Cost-effectiveness Group, CDC Diabetes Cost-effectiveness Group. Cost-Effectiveness of intensive glycemic control, intensified hypertension control, and serum cholesterol level reduction for type 2 diabetes. JAMA 2002;287:2542.

50 Knowler WC, Fowler SE, Hamman RF, et al. 10-Year follow-up of diabetes incidence and weight loss in the diabetes prevention program outcomes study. Lancet 2009;374:1677-86.

51 Selvin E, Steffes MW, Zhu H, et al. Glycated hemoglobin, diabetes, and cardiovascular risk in nondiabetic adults. $N$ Engl $\mathrm{J}$ Med 2010;362:800-11.

52 Kuo HS, Chang HJ, Chou P, et al. A Markov chain model to assess the efficacy of screening for non-insulin dependent diabetes mellitus (NIDDM). Int J Epidemiol 1999;28:233-40.

53 Icks A, Rathmann W, Haastert B, et al. Cost-Effectiveness of type 2 diabetes screening: results from recently published studies. Gesundheitswesen 2005;67:167-71.

54 Roper NA, Bilous RW, Kelly WF, et al. Cause-Specific mortality in a population with diabetes: South Tees diabetes mortality study. Diabetes Care 2002;25:43-8.

55 Meigs JB, Muller DC, Nathan DM, et al. The natural history of progression from normal glucose tolerance to type 2 diabetes in the Baltimore longitudinal study of aging. Diabetes 2003;52:1475-84.

56 Bonora E, Kiechl S, Willeit J, et al. Population-Based incidence rates and risk factors for type 2 diabetes in white individuals: the Bruneck study. Diabetes 2004;53:1782-9.

57 Wein P, Beischer N, Harris C, et al. A trial of simple versus intensified dietary modification for prevention of progression to diabetes mellitus in women with impaired glucose tolerance. Aust N Z J Obstet Gynaecol 1999;39:162-6.

58 Knowler WC, Barrett-Connor E, Fowler SE, et al. Reduction in the incidence of type 2 diabetes with lifestyle intervention or metformin. N Engl J Med 2002;346:393-403.

59 Chiasson J-L, Josse RG, Gomis R, et al. Acarbose for prevention of type 2 diabetes mellitus: the STOP-NIDDM randomised trial. The Lancet 2002;359:2072-7.

60 de Vegt F, Dekker JM, Jager A, et al. Relation of impaired fasting and postload glucose with incident type 2 diabetes in a Dutch population: the Hoorn study. JAMA 2001;285:2109-13.

61 Edelstein SL, Knowler WC, Bain RP, et al. Predictors of progression from impaired glucose tolerance to NIDDM: an analysis of six prospective studies. Diabetes 1997;46:701-10.

62 Eriksson J, Lindström J, Valle T, et al. Prevention of type II diabetes in subjects with impaired glucose tolerance: the Diabetes Prevention Study (DPS) in Finland. study design and 1-year interim report on the feasibility of the lifestyle intervention programme. Diabetologia 1999;42:793-801.

63 Eriksson JG, Lehtovirta M, Ehrnström B, et al. Long-Term beneficial effects of glipizide treatment on glucose tolerance in subjects with impaired glucose tolerance. J Intern Med 2006;259:553-60.
64 Jarrett RJ, Keen H, Fuller JH, et al. Worsening to diabetes in men with impaired glucose tolerance ("borderline diabetes"). Diabetologia 1979;16:25-30.

65 Wareham NJ, Byrne CD, Williams R, et al. Fasting proinsulin concentrations predict the development of type 2 diabetes. Diabetes Care 1999;22:262-70.

66 Rasmussen SS, Glümer C, Sandbaek A, et al. Progression from impaired fasting glucose and impaired glucose tolerance to diabetes in a high-risk screening programme in general practice: the ADDITION study, Denmark. Diabetologia 2007;50:293-7.

67 The DECODE study group. Glucose tolerance and mortality: comparison of WHO and American Diabetes Association diagnostic criteria.. Lancet 1999;354:617-21.

68 Rossing P, Hougaard P, Borch-Johnsen K, et al. Predictors of mortality in insulin dependent diabetes: 10 year observational follow up study. BMJ 1996;313:779-84.

69 Perreault L, Kahn SE, Christophi CA, et al. Regression from prediabetes to normal glucose regulation in the diabetes prevention program. Diabetes Care 2009;32:1583-8.

70 Barr ELM, Magliano DJ, Polkinghorne KR, et al. The Australian diabetes, obesity and lifestyle study, 2006.

71 Oizumi T. [Epidemiologic investigation on the incidence of diabetes mellitus from impaired glucose tolerance in population based study] Nihon Rinsho 2005;63 Suppl 2:73-7.

72 Kawamori R, Tajima N, Iwamoto Y, et al. Voglibose for prevention of type 2 diabetes mellitus: a randomised, double-blind trial in Japanese individuals with impaired glucose tolerance. Lancet 2009;373:1607-14.

73 Nakagami T, DECODA Study Group. Hyperglycaemia and mortality from all causes and from cardiovascular disease in five populations of Asian origin. Diabetologia 2004;47:385-94.

74 Orchard TJ, Temprosa M, Goldberg R, et al. The effect of metformin and intensive lifestyle intervention on the metabolic syndrome: the diabetes prevention program randomized trial. Ann Intern Med 2005;142:611-9.

75 Fox CS, Pencina MJ, Meigs JB, et al. Trends in the incidence of type 2 diabetes mellitus from the 1970s to the 1990s: the Framingham heart study. Circulation 2006;113:2914-8.

76 Lakka H-M, Laaksonen DE, Lakka TA, et al. The metabolic syndrome and total and cardiovascular disease mortality in middle-aged men. JAMA 2002;288:2709-16.

77 Moss SE, Klein R, Klein BE. Cause-Specific mortality in a population-based study of diabetes. Am J Public Health 1991;81:1158-62.

78 Fuller JH, Stevens LK, Wang SL. Risk factors for cardiovascular mortality and morbidity: the WHO multinational study of vascular disease in diabetes. Diabetologia 2001;44 Suppl 2:S54-64.

79 Tuomilehto J, Lindström J, Eriksson JG, et al. Prevention of type 2 diabetes mellitus by changes in lifestyle among subjects with impaired glucose tolerance. N Engl J Med 2001;344:1343-50.

80 Pan XR, Hu YH, Li GW, et al. Impaired glucose tolerance and its relationship to ECG-indicated coronary heart disease and risk factors among Chinese. The Da Qing IGT and diabetes study. Diabetes Care 1993;16:150-6.

81 Harris MI, Klein R, Welborn TA, et al. Onset of NIDDM occurs at least 4-7 yr before clinical diagnosis. Diabetes Care 1992;15:815-9.

82 Pan XR, Li GW, Hu YH, et al. Effects of diet and exercise in preventing NIDDM in people with impaired glucose tolerance. The Da Qing IGT and diabetes study. Diabetes Care 1997;20:537-44.

83 Jia WP, Pang C, Chen L, et al. Epidemiological characteristics of diabetes mellitus and impaired glucose regulation in a Chinese adult population: the Shanghai diabetes studies, a cross-sectional 3-year follow-up study in Shanghai urban communities. Diabetologia 2007;50:286-92.

84 Dunstan DW, Zimmet PZ, Welborn TA, et al. The rising prevalence of diabetes and impaired glucose tolerance: the Australian diabetes, obesity and lifestyle study. Diabetes Care 2002;25:829-34.

85 Balk EM, Earley A, Raman G, et al. Combined diet and physical activity promotion programs to prevent type 2 diabetes among persons at increased risk: a systematic review for the community preventive services task force. Ann Intern Med 2015;163:437-51.

86 The DECODE Study Group. Is the current definition for diabetes relevant to mortality risk from all causes and cardiovascular and noncardiovascular diseases? Diabetes Care 2003;26:688-96. 